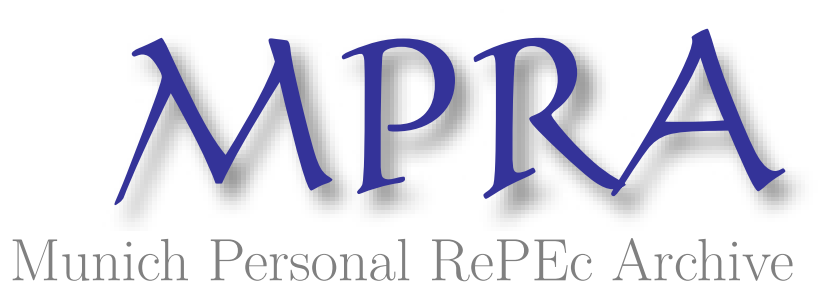

\title{
Macro-finance VARs and bond risk premia: a caveat
}

Taboga, Marco

Bank of Italy

14 November 2008

Online at https://mpra.ub.uni-muenchen.de/11585/

MPRA Paper No. 11585, posted 15 Nov 2008 04:10 UTC 


\title{
Macro-finance VARs and bond risk premia: a caveat
}

\author{
Marco Taboga \\ Banca d'Italia*, Research Department, Financial Markets Unit \\ (marco.taboga@bancaditalia.it)
}

November 14, 2008

\begin{abstract}
Around the turn of the Twentieth century, US and euro area long-term bond yields experienced a remarkable decline and remained at historically low levels even in the face of rising short-term rates (the so called "conundrum"). This unusual phenomenon has been analyzed by many researchers through the lens of macro-finance VARs and no-arbitrage term structure models. A commonly found result is that the decline in longterm rates was primarily driven by an unprecedented reduction in risk premia. I show that such result might be an artefact of the class of models employed to study the phenomenon. I propose an alternative model which suggests that, although risk premia played an important role in reducing bond yields, other two equally important forces were at play, i.e. a decline in the real natural rate of interest and a structural reduction in inflation expectations. I conclude that, after accounting for permanent shifts in the expectations about the future path of short-term rates, the dynamics of risk premia observed after the turn of the century have not been unusual if considered from an historical perspective.
\end{abstract}

${ }^{*}$ The views expressed in the article are those of the author and do not involve the responsibility of the bank. I wish to thank for their helpful comments: Paolo Angelini, Umberto Cherubini, Giuseppe Grande, Marcello Pericoli and participants at the "New Directions in Term Structure Modelling" Conference. 
The sharp decline in long-term interest rates experienced around the turn of the Twentieth century in the major industrialized countries has attracted considerable attention from both academic researchers and policy makers. An especially striking phenomenon has been the fact that long-term rates remained low even in the face of rising short-term rates, which former Federal Reserve chairman Alan Greenspan dubbed a "conundrum" .

A commonly held opinion is that the low level of long-term rates could be largely explained by a decline in the compensation for risk. Such opinion has been supported by much empirical work devoted to the measurement of bond risk premia and the analysis of their dynamics: see, for example, Kim and Wright (2005), Kremer and Rostagno (2006) and Backus and Wright (2007). More mixed evidence is provided by Rudebusch, Swanson and Wu (2006).

In this paper, I argue that models commonly employed to study recent developments in long-term rates might fail to capture permanent changes in the economy that have contributed to lower bond yields; as a consequence, such models might underestimate the level of risk premia in more recent years and overemphasize the severity of the bond yield conundrum.

Standard term-structure theory identifies two main drivers behind movements in long-term rates: changes in the expected future path of the short-term rate and fluctuations in risk premia. I provide some evidence that popular termstructure models, based on stationary vector autoregressions (VARs) ${ }^{2}$, might be unable to detect long-lasting shifts in the expectations about the short-term rate. Such models tend to attribute most of the variability in long-term forward interest rates to forward premia and little or almost none to changing expectations. The technical reason for this problem is that estimated VARs often display a fast speed of convergence to their unique equilibrium and produce forecasts of the short-term rate at long horizons which remain roughly constant through time and are hardly different from their historical averages.

I propose to use a simple macroeconometric model in which permanent shifts in the natural real rate of interest ${ }^{3}$, the growth rate of potential output and longrun inflation determine long-lasting changes in expectations about the shortterm rate. Any permanent change in one of these three variables determines a new set of equilibrium values towards which all the other macroeconomic variables of interest tend to converge.

Estimates of the model suggest that in recent years a reduction in both

\footnotetext{
1 "Long-term interest rates have trended lower in recent months even as the Federal Reserve has raised the level of the target federal funds rate by 150 basis points. This development contrasts with most experience, which suggests that, other things being equal, increasing short-term interest rates are normally accompanied by a rise in longer-term yields... for the moment, the broadly unanticipated behavior of world bond markets remains a conundrum" (Testimony of federal Reserve Board Chairman Alan Greenspan to the U.S. Senate, February 16 th, 2005).

${ }^{2}$ The same comments apply to VAR's continuos-time counterparts, such as multifactor Vasicek (1977) and Cox-Ingersoll-Ross (1985) models.

${ }^{3}$ In the model I propose, which is an extension of the model by Laubach and Williams (2003), the natural rate of interest is defined as in Wicksell (1936) as the real short-term interest rate consistent with a macroeconomic equilibrium in which output equals its potential and inflation is constant.
} 
the real natural rate of interest and inflation expectations lowered long-term forecasts of the level of policy rates, both in the US and in the euro area. According to my model, this was an important cause of the fall in long-term bond yields, which, if overlooked, might lead to erroneously attribute the fall to a collapse of risk premia. The main inference to be drawn from the model is that, although risk premia did diminish, the fall was not dramatic and their current level is not unusual if considered from an historical perspective.

The paper is organized as follows: Section 1 discusses the challenges related to the estimation of risk premia and the possible drawbacks of standard econometric models; Section 2 presents the model I use to measure risk premia; Section 3 discusses some details of the estimation methodology; Section 4 contains some comments on the empirical evidence obtained with the model; the Appendix includes tables, figures and some technical details of the model.

\section{Motivation}

In this section I discuss the problems that might arise when one relies on standard stationary macro-finance VARs (and their continuous-time counterparts; see footnote 3) to estimate bond risk premia. A related discussion can be found in Kim and Orphanides (2005).

Among the many possible measures of the risk premium, I focus on the simplest and most straightforward: the forward premium, i.e. the difference between $f_{t, t+n}$ (the forward rate at which agents agree at time $t$ to exchange funds at time $t+n$ for one period) and $\mathrm{E}_{t}\left[i_{t+n}\right]$ (the expected value of $i_{t+n}$ given information available at time $t$, where $i_{t+n}$ is the short-term rate at which agents will agree to exchange funds at time $t+n$ for the next period). Thus, the $n$-periods ahead forward premium $\varphi_{t, t+n}$ is defined as:

$$
\varphi_{t, t+n}=f_{t, t+n}-\mathrm{E}_{t}\left[i_{t+n}\right]
$$

Focusing on the forward premium is without loss of generality, because any bond yield can be decomposed into a sequence of forward rates at which agents agree today to exchange funds in the future.

Since forward rates $f_{t, t+n}$ are observable from market prices, the above equation makes clear that the whole challenge of measuring forward premia lies in accurately estimating unobservable expectations $\mathrm{E}_{t}\left[i_{t+n}\right]$ of short-term rates likely to prevail in the future.

In order to estimate $\mathrm{E}_{t}\left[i_{t+n}\right]$, a possibility would be to directly survey market participants' expectations about future levels of the interest rate. However, most existing studies rely on econometric models to estimate expectations about interest rates. A reason for doing so is that typically available survey data have limited historical depth, so that their time series properties and their reliability are difficult, if not impossible, to study; on the contrary, simple macro-econometric models use long time-series of readily available macroeconomic data, allowing the researcher to achieve sufficient historical perspective when studying the behavior of expectations and risk premia. Furthermore, some 
papers (e.g.: Friedman - 1980; Froot - 1989) have provided evidence that the informative content of interest rate survey forecasts might be questionable.

Most of the econometric models which have been employed to analyze the term structure of interest rates share a similar structure: they specify the joint dynamics of the short-term interest rate and of a small number of other variables as a vector autoregression (or as a continuous-time model which can be discretized so as to yield a vector autoregression - see footnote 3 ). The other variables in the VAR are usually macroeconomic variables, such as inflation and the output gap, and variables explicitly or implicitly related to the shape of the yield curve. For example, Estrella and Mishkin (1997) and Evans and Marshall (1998) estimate VARs with yields of various maturities and macroeconomic variables. Numerous studies estimate no-arbitrage latent factor models where macroeconomic variables do not play any role (e.g.: Duffie and Kan 1996; Dai and Singleton - 2000). Recently, a number of papers, starting with the seminal work by Ang and Piazzesi (2003), have jointly modeled both macroeconomic variables and (latent) variables related to the shape of the yield curve as VARs with full no-arbitrage restrictions (e.g.: Rudebusch and $\mathrm{Wu}-2004$; Hordal, Tristani and Vestin - 2006; Ang, Piazzesi and Wei - 2006).

All the aforementioned models can in principle be used to estimate expectations of the future path of short-term rates. However, as carefully illustrated by Kim and Orphanides (2005), estimates of long-horizon expectations provided by such models can be seriously misleading. While there is ample empirical and anectodal evidence that considerable structural changes took place in the major industrialized economies and reduced long-run expectations of the short rate (e.g.: Campbell and Viceira - 2001; Clarida, Gali and Gertler - 2000; Cogley and Sargent - 2001; Derby - 2004; Goto and Torus - 2003), most of these models provide estimates of long-horizon expectations which remain virtually unchanged across time. To capture structural breaks and produce enough variation in long-term expectations, estimated VARs should have at least one highly persistent factor with long half-life; however, it is well known that the very presence of such persistent factors makes estimation of VARs problematic, because of finite sample biases and inefficiencies of standard estimators, such as maximum likelihood ones. Most of the times, even if the true data-generating process features persistent factors, this is unlikely to show up in the estimates. Kim and Orphanides (2005), for example, estimate a standard no-arbitrage term structure model which, in principle, could allow for one or more persistent factors and show that, despite the presence of obvious structural breaks in their sample, the model is unable to detect them and produces estimates of long-run expectations wich are roughly constant across time. Furthermore, the choice of the sample lenght is bound to heavily influence the results and the level of estimated expectations. Below, I provide further evidence in this sense.

In Figure 1, I plot the 9-year ahead expectations of the short rate obtained from a standard macro-VAR with 12 lags of inflation, the output gap and the short rate, estimated with quarterly US data covering the period 1965-2006. The same figure also displays the plot of the 9-year ahead forward-rate. The difference between the two series is an estimate of the forward premium. It is 
apparent that the measure of expectations thus obtained is very stable throughout the whole period: approximately 80 per cent of the values are between 6 and 7 per cent and the average expectation is 6.67 per cent, which almost coincides with the sample average of the short-term rate, which is 6.66. After the year 2000, model-implied expectations have on average been roughly equal to 6.5 per cent. This is in sharp contrast with statements from policy makers, who suggested a range of 3.5 to 4.5 per cent (see e.g.: Derby - 2004; Hoenig 2005), and with survey forecasts (Kim and Orphanides - 2005). Reducing the sample period used to estimate the model, in order to mitigate the problems arising from structural breaks, does not seem to produce improvements: estimated expectations still remain roughly constant across time; however, their average shifts considerably, depending on the sample period I choose, pointing to a severe lack of robustness of the results with respect to sample choice.

If instead of a standard macro-VAR, I estimate a no-arbitrage VAR with both macroeconomic and latent variables (in the canonical form suggested by Pericoli and Taboga - 2008), which in principle should be able to identify persistent factors and capture structural change, I get results which are slightly better, in the sense that the model produces a somewhat greater variability of expectations (see Figure 2). Nonetheless, estimated expectations still look very stable (if compared with forward rates), they are at odds with market participants' and policymaker's perceptions during the most recent period and they also display limited robustness to sample choice.

Estimates for the euro area of both standard and no-arbitrage VARs (Figures 7 and 8) present drawbacks that are similar to those of the estimates carried out for the US and commented above.

As a solution to the aforementioned problems, I propose a simple model where some key variables are affected by permanent shocks which dynamically induce shifts in macroeconomic equilibria: long-run inflation expectations, the real natural rate of interest and the growth rate of potential output are identified as the sources of persistence which have a potential to capture structural change and generate the desired variation in long-term expectations. To impose persistence on the variables driving structural change, I model the corresponding stochastic processes as random walks, so that the resulting economic dynamics be not explosive, but rather allow for time-varying equilibria.

\section{The model}

My model is an extension of the model used by Laubach and Williams (2003) to estimate the natural rate of interest. According to the Wicksellian definition (Wicksell - 1936), the natural rate of interest is the real short-term interest rate consistent with a macroeconomic equilibrium in which output equals its potential and inflation is constant. The natural rate varies through time in response to structural changes in the economy: most theoretical frameworks underline its dependce on productivity growth, population growth, the subjective discount factor of individuals, their elasticity of intertemporal substitution and other 
characteristics of agents' preferences and production technologies which tend to be subject to permanent shocks.

While Laubach and Williams do not specify an equation for the nominal short-term interest rate and estimate the real natural rate of interest only via estimation of an IS equation and an inflation equation, I add an equation for the nominal short-term interest rate to their model, so as to be able to recover interest rate dynamics and their dependence on the real natural rate of interest and other macroeconomic variables: thus, I have a device through which changes in the real natural rate of interest are transmitted to the nominal short-term rate and to expectations about its path in the long-run. Furthermore, while Laubach and Williams use proxies for inflation expectations, I use proper expectations, consistently derived within the model. As the equations to follow will clarify, this is a source of transmission of long-run shifts in inflation expectations.

The first building block of the model is a reduced form IS equation (see e.g. Rudebusch and Svensson - 1999):

$$
x_{t}=\alpha_{1} x_{t-1}+\alpha_{2} x_{t-2}+\frac{\alpha_{r}}{2} \sum_{j=1}^{2}\left(r_{t-j}-r_{t-j}^{*}\right)+\varepsilon_{x, t}
$$

where $x_{t}$ is the output gap, $r_{t}$ is the ex-ante real policy rate, $r_{t}^{*}$ is the real natural rate of interest and $\varepsilon_{x, t}$ is a serially uncorrelated shock. Provided $\alpha_{r}$ is negative, when the real policy rate is above (below) the natural rate, monetary policy is contractionary (expansionary) and output tends to decrease (increase).

The output gap is defined as:

$$
x_{t}=y_{t}-y_{t}^{*}
$$

where $y_{t}$ and $y_{t}^{*}$ are the logarithms of output and potential output respectively. The ex-ante real policy rate is the difference between the policy rate $i_{t}$ and inflation expectations:

$$
r_{t}=i_{t}-E_{t}\left[\pi_{t+1}\right]
$$

Inflation $\pi_{t}$ is determined by its own lags, lagged output gap and a serially uncorrelated shock:

$$
\pi_{t}=\sum_{j=1}^{8} \beta_{j} \pi_{t-j}+\beta_{x} x_{t-1}+\varepsilon_{\pi, t}
$$

The constraints $\sum_{j=1}^{8} \beta_{j}=1$ and $\beta_{j} \geqslant 0, \forall j$ are imposed to ensure verticality of the Phillips curve in the long-run (see e.g. Rudebusch and Svensson 1999). Besides being able to capture rather rich inflation dynamics, the above specification of the Phillips curve is consistent with the Wicksellian definition of natural rate: together with equation (2) and (6), it implies that, absent any transitory shock to the economy and when the real short-term rate equals the natural rate, output converges to its potential and inflation converges to a constant level. Long-run verticality of the Phillips curve means that any level of 
inflation can be compatible with an economic equilibrium where output equals its potential. I stick to the original backward-looking specification proposed by Laubach and Williams (2003), because it allows for a closed-form solution of the model (see the Appendix).

Adjustments in the nominal short-term rate happen in accordance with the following equation:

$$
i_{t}=\gamma i_{t-1}+(1-\gamma)\left(i_{t-1}^{n}+\gamma_{\pi}\left(\bar{\pi}_{t-1}-\pi_{t-1}^{*}\right)+\gamma_{x} x_{t-1}\right)+\varepsilon_{i, t}
$$

where $i_{t}^{n}$ is the nominal natural rate of interest, defined as:

$$
i_{t}^{n}=r_{t}^{*}+E_{t}\left[\pi_{t+1}\right]
$$

$\pi_{t}^{*}$ is long-run inflation:

$$
\pi_{t}^{*}=\pi_{t-1}^{*}+\varepsilon_{\pi^{*}, t}
$$

and $\bar{\pi}_{t}$ is a measure of realized inflation, defined as:

$$
\bar{\pi}_{t}=\frac{1}{4} \sum_{j=0}^{3} \pi_{t-j}
$$

Equation (6) could be interpreted as a smoothing policy rule (e.g.: Bjornland, Leitemo and Maih - 2006), whereby the central bank gradually raises interest rates when either output is above its potential or realized inflation is above the desired long-run level $\pi_{t}^{*}$. Provided $\gamma_{\pi}$ and $\gamma_{x}$ are strictly positive and $\gamma$ is strictly less than 1, (6) guarantees that, in the absence of transitory shocks, the economy converges towards an equilibrium where output equals its potential, inflation is equal to its long-run level and the real short-term rate equals the real natural rate of interest. This allows for multiple equilibria that differ as to the level of inflation and the interest rate. This is the key feature of the model, which makes it suitable to reproduce the structural changes and the permanent shifts in long-run expectations not captured by standard stationary VARs. Specifying long-run inflation $\pi_{t}^{*}$ as a random walk, I allow for permanent unpredictable changes in the equilibrium level of inflation: the variance of the innovation $\varepsilon_{\pi^{*}, t}$ determines the expected magnitude of such changes.

Potential output grows at a rate $g_{t}$

$$
y_{t}^{*}=y_{t-1}^{*}+g_{t-1}
$$

which varies through time as a random walk:

$$
g_{t}=g_{t-1}+\varepsilon_{g, t}
$$

Finally, the natural real rate of interest is the sum of two terms:

$$
r_{t}^{*}=c g_{t}+z_{t}
$$


where $c$ is a constant related to the elasticity of intertemporal substitution and $z_{t}$ is a shock that captures other determinants of $r_{t}^{*}$ such as the subjective discount factor. Also $z_{t}$ is specified as a random walk:

$$
z_{t}=z_{t-1}+\varepsilon_{z, t}
$$

Equation (12) can be derived, for example, within a standard Solow or Ramsey growth model (e.g.: Barro and Sala-i-Martin - 1999), where it is related either to a balanced growth condition or to an optimality condition for savings.

In order to be able to jointly estimate the forward premium and the macroeconomic dynamics specified by the above equations, I add to the system an exogenous process for the forward premium:

$$
\varphi_{t}=\varphi_{t-1}+\varepsilon_{\varphi, t}
$$

The model can be written explicitly in companion form as a first order vector autoregression, by substituting inflation expectations with their value derived from (5). Details are reported in the Appendix.

\section{$3 \quad$ Estimation strategy}

I estimate the model by maximum likelihood, with both US and euro area quarterly data (see the Appendix for details on the data). I adopt the methodology proposed by Boivin and Giannoni (2005) for estimation in data-rich environments: all the variables in the model are treated as unobservable, in order to allow for measurement errors and for the possibility that many data series be available for a single economic concept ${ }^{4}$. An observation equation is defined for any data series, so that there can be multiple observation equations for a single variable. The observation equations are used to infer the values of the variables of the model via the Kalman filter.

As previously observed, my model can be written in companion form as a first order vector autoregression:

$$
\xi_{t}=F \xi_{t-1}+v_{t}
$$

where $\xi_{t}$ is a column vector that contains all the variables of the model and some of their lags:

$\xi_{t}=\left[\begin{array}{lllllllllllllll}x_{t} & \pi_{t} & i_{t} & y_{t}^{*} & z_{t} & g_{t} & \pi_{t}^{*} & x_{t-1} & g_{t-1} & z_{t-1} & \pi_{t-1} & \ldots & \pi_{t-8} & i_{t-1} & \varphi_{t}\end{array}\right]^{\top}$

$F$ is a matrix whose entries are determined by the solution of the model in the previous section (the functional form of the coefficients is reported in the Appendix) and $v_{t}$ is a vector of error terms.

\footnotetext{
${ }^{4}$ In what follows, I use the same terminology of Boivin and Giannoni (2005): an 'economic variable' is one of the variables in the model (whose concept is uniquely defined); a 'data series' is one of the many possible measures of the variable. For example, if inflation is a variable in the model, many data series could be used to measure it: CPI (consumer prices) inflation, core-CPI, GDP deflator, PCE (personal consumption expenditures) deflator, etc.
} 
All the variables in $\xi_{t}$ are treated as unobservable. Their values are estimated by the Kalman filter, using a set of observation equations:

$$
y_{t}=H \xi_{t}+w_{t}
$$

where $y_{t}$ is the vector of observed data series used to measure the unobservable variables, $H$ is a matrix of loadings (see the Appendix for details) and $w_{t}$ is a vector of error terms.

The procedure proposed by Boivin and Giannoni (2005) is motivated by the observation that: 1) many measures of economic variables are likely to be affected by measurement error; 2) there may be conceptual differences between model variables and the data series used to measure them; 3) there may be many different data series that correspond to a unique economic concept; 4) one might want to use data series which are proxies for unobservable or only partially observable variables. I choose to adopt Boivin and Giannoni's (2005) procedure, because I have many measures of inflation and all of them are potentially relevant to my model; furthermore, I have estimates and proxies of some unobservable variables (potential output, long-run inflation), which I want to exploit in order to achieve a better identification of unobservables.

The vector $y_{t}$ includes: real GDP, an estimate of potential GDP, two different measures of inflation, the 3-month interest rate, the 9-year-ahead forward interest rate ${ }^{5}$ and a consensus forecast of long-run inflation ${ }^{6}$ (a detailed list of the data series and their sources, both for the US and for the euro area, is included in the Appendix).

\section{Empirical evidence}

From the estimates of the model ${ }^{7}$ (estimated parameters are reported in Tables 2 and 3), similar pictures emerge for both the US and the euro area. Long-run inflation expectations and the real natural rate (Figures 4 and 10) underwent significant changes throughout the sample period. As a result, also long-run expectations of the short-term interest rate displayed a fair degree of variability (Figures 3 and 9). This is in sharp contrast with the evidence provided by traditional macro-VAR and no-arbitrage term-structure models (Figures 1, 2, 7 and 8 ), whereby expectations would have remained remarkably stable throughout the whole sample. My model suggests that, since the late Eighties, long-run expectations of the short-rate have considerably declined, both in the US and in the euro area, as a consequence of a progressive reduction in the real natural

\footnotetext{
${ }^{5}$ It is standard practice in the literature to take the forward premium on the 9-year ahead forward rate as a measure of the risk premium embedded in long-term interest rates (e.g.: Kim and Orphanides - 2005).

${ }^{6}$ Both for the US and for the euro area, consensus forecasts of long-run inflation are available only for a subsample of the whole sample period. I nonetheless use them by augmenting the set of observation equations after they become available.

${ }^{7}$ In the tables and figures in the Appendix, the model described in sections 2 and 3 is referred to as "model with multiple equilibria", to distinguish it from traditional VAR models with a unique equilibrium.
} 
rate and inflation expectations. Between 1990 and 2006, long-run inflation decreased from 4.50 to 1.95 in the euro area and from 4.40 to 2.30 in the US; the real natural rate decreased from 5.70 to 1.65 in the euro area and from 2.90 to 1.90 in the US. Taking these developments into account, I obtain estimates of the forward premium (Figures 5, 6, 11 and 12) which are materially different from those provided by standard models, especially as far as the last decade is concerned. Although the forward premium dropped sharply after 2002 in both economies, it fell to levels which are not at all unusual from an historical perspective and it is still broadly positive. At the end of 2006, the 9-year ahead forward premium was estimated to be 0.45 percentage points in the euro area and 1.90 points in the US. Hence, although previous studies correctly identify a fall in risk premia as an important cause of the recent pronounced reduction in bond yields, they probably tend to exaggerate the phenomenon, because they overlook shifts in expectations which hardly allow for a direct comparison of the current level of bond yields with that of ten or twenty years ago.

\section{Conclusions}

Decomposing forward interest rates into forward premia and expectations of spot interest rates that will prevail in the future is key to understanding the dynamics of long-term bond yields. I have shown that estimates of distanthorizon expectations provided by commonly employed VAR models display little or no variability and tend to attribute most of the variabilty in forward rates to forward premia. This is due to a lack of persistence of estimated shocks to short-term interest rates and macroeconomic variables. I propose a model that allows for more persistence and allows to capture substantial changes in distant-

horizon expectations. Employing my model to study the historical evolution of long-term rates, I conclude that the sharp decline in long-term interest rates experienced around the turn of the Twentieth century in the major industrialized countries has been due to a progressive fall in expected future rates rather than to a collapse in risk premia, as other models seem to suggest. 


\section{Appendix}

In order to write the model explicitly, I substitute inflation expectations in the

IS equation and in the policy rule with their explicit expression derived from $(5)$ :

$$
\begin{aligned}
& x_{t}=\alpha_{1} x_{t-1}+\alpha_{2} x_{t-2}+\frac{\alpha_{r}}{2} \sum_{j=1}^{2}\left(r_{t-j}-r_{t-j}^{*}\right) \\
& =\alpha_{1} x_{t-1}+\alpha_{2} x_{t-2}+\frac{\alpha_{r}}{2} \sum_{j=1}^{2}\left(i_{t-j}-E_{t-j}\left[\pi_{t-j+1}\right]-r_{t-j}^{*}\right) \\
& =\alpha_{1} x_{t-1}+\alpha_{2} x_{t-2}+\frac{\alpha_{r}}{2} i_{t-1}+\frac{\alpha_{r}}{2} i_{t-2}-\frac{\alpha_{r}}{2} r_{t-1}^{*}-\frac{\alpha_{r}}{2} r_{t-2}^{*} \\
& -\frac{\alpha_{r}}{2}\left(\sum_{j=1}^{8} \beta_{j} \pi_{t-j}+\beta_{x} x_{t-1}\right)-\frac{\alpha_{r}}{2}\left(\sum_{j=2}^{9} \beta_{j-1} \pi_{t-j}+\beta_{x} x_{t-2}\right) \\
& =\left(\alpha_{1}-\frac{\alpha_{r}}{2} \beta_{x}\right) x_{t-1}+\left(\alpha_{2}-\frac{\alpha_{r}}{2} \beta_{x}\right) x_{t-2}+\frac{\alpha_{r}}{2} i_{t-1}+\frac{\alpha_{r}}{2} i_{t-2}-\frac{\alpha_{r}}{2} z_{t-1}-\frac{\alpha_{r}}{2} z_{t-2} \\
& -\frac{\alpha_{r}}{2} c g_{t-1}-\frac{\alpha_{r}}{2} c g_{t-2}-\frac{\alpha_{r}}{2}\left(\beta_{1} \pi_{t-1}+\left(\beta_{1}+\beta_{2}\right) \pi_{t-2}+\left(\beta_{2}+\beta_{3}\right) \pi_{t-3}\right) \\
& -\frac{\alpha_{r}}{2}\left(\left(\beta_{3}+\beta_{4}\right) \pi_{t-4}+\left(\beta_{4}+\beta_{5}\right) \pi_{t-5}+\left(\beta_{5}+\beta_{6}\right) \pi_{t-6}\right) \\
& -\frac{\alpha_{r}}{2}\left(\left(\beta_{6}+\beta_{7}\right) \pi_{t-7}+\left(\beta_{7}+\beta_{8}\right) \pi_{t-8}+\beta_{8} \pi_{t-9}\right) \\
& i_{t}=\gamma i_{t-1}+(1-\gamma)\left(i_{t-1}^{n}+\gamma_{\pi}\left(\bar{\pi}_{t-1}-\pi_{t-1}^{*}\right)+\gamma_{x} x_{t-1}\right) \\
& =\gamma i_{t-1}+(1-\gamma)\left(r_{t-1}^{*}+E_{t-1}\left[\pi_{t}\right]\right)+(1-\gamma) \gamma_{\pi} \frac{1}{4} \sum_{j=1}^{4} \pi_{t-j} \\
& -(1-\gamma) \gamma_{\pi} \pi_{t-1}^{*}+(1-\gamma) \gamma_{x} x_{t-1} \\
& =\gamma i_{t-1}+(1-\gamma) c g_{t-1}+(1-\gamma) z_{t-1}+(1-\gamma)\left(\sum_{j=1}^{8} \beta_{j} \pi_{t-j}+\beta_{x} x_{t-1}\right) \\
& +(1-\gamma) \gamma_{\pi} \frac{1}{4} \sum_{j=1}^{4} \pi_{t-j}-(1-\gamma) \gamma_{\pi} \pi_{t-1}^{*}+(1-\gamma) \gamma_{x} x_{t-1} \\
& =\gamma i_{t-1}+(1-\gamma) c g_{t-1}+(1-\gamma) z_{t-1}+(1-\gamma)\left(\beta_{x}+\gamma_{x}\right) x_{t-1}-(1-\gamma) \gamma_{\pi} \pi_{t-1}^{*} \\
& +(1-\gamma)\left(\left(\beta_{1}+\gamma_{\pi} \frac{1}{4}\right) \pi_{t-1}+\left(\beta_{2}+\gamma_{\pi} \frac{1}{4}\right) \pi_{t-2}+\left(\beta_{3}+\gamma_{\pi} \frac{1}{4}\right) \pi_{t-3}\right) \\
& +(1-\gamma)\left(\left(\beta_{4}+\gamma_{\pi} \frac{1}{4}\right) \pi_{t-4}+\beta_{5} \pi_{t-5}+\beta_{6} \pi_{t-6}+\beta_{7} \pi_{t-7}+\beta_{8} \pi_{t-8}\right)
\end{aligned}
$$


Now, define the vector $\xi_{t}$ as follows:

$\xi_{t}=\left[\begin{array}{lllllllllllllll}x_{t} & \pi_{t} & i_{t} & y_{t}^{*} & z_{t} & g_{t} & \pi_{t}^{*} & x_{t-1} & g_{t-1} & z_{t-1} & \pi_{t-1} & \ldots & \pi_{t-8} & i_{t-1} & \varphi_{t}\end{array}\right]^{\top}$

The whole model can be written in companion form as a first order vector autoregression:

$$
\xi_{t}=F \xi_{t-1}+v_{t}
$$

The non-zero entries of the companion matrix $F$ are as follows $\left(F_{i, j}\right.$ denotes the entry at the intersection of the $i$-th row and $j$-th column):

$$
\begin{aligned}
& F_{1,1}=\alpha_{1}-\frac{\alpha_{r}}{2} \beta_{x} ; F_{1,2}=-\frac{\alpha_{r}}{2} \beta_{1} ; F_{1,3}=\frac{\alpha_{r}}{2} ; F_{1,5}=-\frac{\alpha_{r}}{2} ; \\
& F_{1,6}=-\frac{\alpha_{r}}{2} c ; F_{1,8}=\alpha_{2}-\frac{\alpha_{r}}{2} \beta_{x} ; F_{1,9}=-\frac{\alpha_{r}}{2} c ; F_{1,10}=-\frac{\alpha_{r}}{2} ; \\
& F_{1,11}=-\frac{\alpha_{r}}{2}\left(\beta_{1}+\beta_{2}\right) ; F_{1,12}=-\frac{\alpha_{r}}{2}\left(\beta_{2}+\beta_{3}\right) ; F_{1,13}=-\frac{\alpha_{r}}{2}\left(\beta_{3}+\beta_{4}\right) ; \\
& F_{1,14}=-\frac{\alpha_{r}}{2}\left(\beta_{4}+\beta_{5}\right) ; F_{1,15}=-\frac{\alpha_{r}}{2}\left(\beta_{5}+\beta_{6}\right) ; F_{1,16}=-\frac{\alpha_{r}}{2}\left(\beta_{6}+\beta_{7}\right) ; \\
& F_{1,17}=-\frac{\alpha_{r}}{2}\left(\beta_{7}+\beta_{8}\right) ; F_{1,18}=-\frac{\alpha_{r}}{2} \beta_{8} ; F_{1,19}=\frac{\alpha_{r}}{2} ; \\
& F_{2,1}=\beta_{x} ; F_{2,2}=\beta_{1} ; F_{2,11}=\beta_{2} ; F_{2,12}=\beta_{3} ; F_{2,13}=\beta_{4} ; F_{2,14}=\beta_{5} ; \\
& F_{2,15}=\beta_{6} ; F_{2,16}=\beta_{7} ; F_{2,17}=\beta_{8} ; \\
& F_{3,1}=(1-\gamma)\left(\beta_{x}+\gamma_{x}\right) ; F_{3,2}=(1-\gamma)\left(\beta_{1}+\gamma_{\pi} \frac{1}{4}\right) ; F_{3,3}=\gamma ; F_{3,5}=(1-\gamma) ; \\
& F_{3,6}=(1-\gamma) c ; F_{3,7}=-(1-\gamma) \gamma_{\pi} ; F_{3,11}=(1-\gamma)\left(\beta_{2}+\gamma_{\pi} \frac{1}{4}\right) ; \\
& F_{3,12}=(1-\gamma)\left(\beta_{3}+\gamma_{\pi} \frac{1}{4}\right) ; F_{3,13}=(1-\gamma)\left(\beta_{4}+\gamma \gamma_{\pi} \frac{1}{4}\right) ; F_{3,14}=(1-\gamma) \beta_{5} ; \\
& F_{3,15}=(1-\gamma) \beta_{6} ; F_{3,16}=(1-\gamma) \beta_{7} ; F_{3,17}=(1-\gamma) \beta_{8} ; \\
& F_{4,4}=1 ; F_{4,6}=1 ; F_{5,5}=1 ; F_{6,6}=1 ; F_{7,7}=1 ; \\
& F_{8,1}=1 ; F_{9,6}=1 ; F_{10,5}=1 ; F_{11,2}=1 ; \\
& F_{12,11}=1 ; F_{13,12}=1 ; F_{14,13}=1 ; F_{15,14}=1 ; \\
& F_{16,15}=1 ; F_{17,16}=1 ; F_{18,17}=1 ; F_{19,3}=1 ; F_{20,20}=1
\end{aligned}
$$

All the remaining entries are zero.

The vector of error terms $v_{t}$ is:

$$
v_{t}=\left[\begin{array}{lllllllllll}
\varepsilon_{x, t} & \varepsilon_{\pi, t} & \varepsilon_{i, t} & 0 & \varepsilon_{z, t} & \varepsilon_{g, t} & \varepsilon_{\pi^{*}, t} & 0 & \ldots & 0 & \varepsilon_{\varphi, t}
\end{array}\right]^{\top}
$$

I denote the variances of the non-zero terms by $\sigma_{x}^{2}, \sigma_{\pi}^{2}, \ldots, \sigma_{\varphi}^{2}$.

The non-zero entries of the matrix of loadings $H$, defining the observation equations are as follows:

$$
\begin{aligned}
& H_{1,2}=1 ; H_{2,2}=1 ; H_{3,1}=1 ; H_{3,4}=1 ; H_{4,4}=1 ; H_{5,3}=1 ; \\
& H_{6, j}=\left(F^{36}\right)_{3, j}, j=1, \ldots, 19 \\
& H_{6,20}=\left(F^{36}\right)_{3,20}+1 \\
& H_{7, j}=\left(F^{40}\right)_{2, j}, j=1, \ldots, 20
\end{aligned}
$$

All the remaining entries are zero. The first two equations correspond to two different inflation data series. The third and fourth equation correspond to output and potential output respectively. The fifth and sixth are the measurement equations for the short-term and the 9-year ahead forward interest rates, respectively. The seventh equation corresponds to long-run (10-year ahead) consensus inflation expectations. 
The variances of the measurement errors in the observation equations are denoted by:

$$
\tau_{j}=\operatorname{Var}\left(w_{j, t}\right), j=1, \ldots, 7
$$


Table 1 - Data and Data Sources

\begin{tabular}{llll} 
& United States & \\
\hline Variable & Source & Sample Period & Acronym \\
\hline US GDP (ar) cona & Datastream & $1961-2006$ & USGDP...D \\
US CBO Forecast - Potential GDP (real) cona & Datastream & $1961-2006$ & USFCGDPPD \\
US CPI - All urban: all items, sadj & Datastream & $1961-2006$ & USCONPRCE \\
US CPI - All items less food \& energy (core), sadj & Datastream & $1961-2006$ & USCPCOREE \\
US Treasury Bill 2nd market 3 month - middle rate & Datastream & $1961-2006$ & FRTBS3M \\
US Zero Coupon Curve (FED estimates) & BIS Databank (BIS_Macro) & $1961-2006$ & HSLA,HSMA \\
Consumer Prices, Long Term Forecasts & Consensus Economics & $1991-2006$ & N/A
\end{tabular}

Euro Area

\begin{tabular}{llll}
\hline Variable & Source & Sample Period & Acronym \\
\hline Real GDP & Euro Area-Wide Model Database & $1970-2006$ & YER \\
Potential Output & Euro Area-Wide Model Database & $1970-2006$ & YET \\
GDP at Factor Costs Deflator & Euro Area-Wide Model Database & $1970-2006$ & YFD \\
HICP & Euro Area-Wide Model Database & $1970-2006$ & HICP \\
Short-term interest rate & Euro Area-Wide Model Database & $1970-2006$ & STN \\
Long-term interest rate & Euro Area-Wide Model Database & $1970-2006$ & LTN \\
Consumer Prices, Long Term Forecasts & Consensus Economics & $1991-2006$ & N/A
\end{tabular}

${ }^{8}$ For a complete description of the dataset see Fagan, Henry and Mestre (2001). 
Table 2

Parameter estimates - US

\begin{tabular}{lll|lll} 
& Est. & St. Dev & & Est. & St. Dev. \\
\hline$\alpha_{1}$ & 1.1096 & 0.0539 & $c$ & 1.5351 & 0.2363 \\
$\alpha_{2}$ & -0.1893 & 0.0455 & $\sigma_{x}$ & 0.0072 & 0.0001 \\
$\alpha_{r}$ & -0.3705 & 0.1207 & $\sigma_{\pi}$ & 0.0110 & 0.0004 \\
$\beta_{1}$ & 0.3624 & 0.0732 & $\sigma_{i}$ & 0.0055 & 0.0008 \\
$\beta_{2}$ & 0 & 0.0565 & $\sigma_{z}$ & 0.0054 & 0.0004 \\
$\beta_{3}$ & 0.4911 & 0.0231 & $\sigma_{g}$ & 0.0002 & 0.0001 \\
$\beta_{4}$ & 0 & 0.0736 & $\sigma_{\pi^{*}}$ & 0.0009 & 0.0001 \\
$\beta_{5}$ & 0 & 0.0365 & $\sigma_{\varphi}$ & 0.0138 & 0.0007 \\
$\beta_{6}$ & 0.0402 & 0.1259 & $\tau_{1}$ & 0.0119 & 0.0007 \\
$\beta_{7}$ & 0 & 0.0010 & $\tau_{2}$ & 0.0103 & 0.0011 \\
$\beta_{8}$ & 0.1063 & 0.0956 & $\tau_{3}$ & 0.0018 & 0.0001 \\
$\beta_{x}$ & 0.2434 & 0.0006 & $\tau_{4}$ & 0 & 0.0012 \\
$\gamma$ & 0.2035 & 0.2802 & $\tau_{5}$ & 0 & 0.0028 \\
$\gamma_{x}$ & 0.2134 & 0.1667 & $\tau_{6}$ & 0.0001 & 0.0002 \\
$\gamma_{\pi}$ & 0.2413 & 0.2450 & $\tau_{7}$ & 0 & 0.0005
\end{tabular}


Table 3

Parameter estimates - Euro Area

\begin{tabular}{lll|lll} 
& Est. & St. Dev & & Est. & St. Dev. \\
\hline$\alpha_{1}$ & 1.5336 & 0.0173 & $c$ & 0 & 0.0488 \\
$\alpha_{2}$ & -0.4851 & 0.0229 & $\sigma_{x}$ & 0.0034 & 0.0004 \\
$\alpha_{r}$ & -0.1842 & 0.0168 & $\sigma_{\pi}$ & 0.0036 & 0.0006 \\
$\beta_{1}$ & 0.8054 & 0.0593 & $\sigma_{i}$ & 0.0054 & 0.0003 \\
$\beta_{2}$ & 0.1907 & 0.0344 & $\sigma_{z}$ & 0.0034 & 0.0004 \\
$\beta_{3}$ & 0.0038 & 0.0112 & $\sigma_{g}$ & 0.0002 & 0.0003 \\
$\beta_{4}$ & 0.0001 & 0.0202 & $\sigma_{\pi^{*}}$ & 0.0009 & 0.0002 \\
$\beta_{5}$ & 0 & 0.0047 & $\sigma_{\varphi}$ & 0.0036 & 0.0007 \\
$\beta_{6}$ & 0 & 0.0098 & $\tau_{1}$ & 0.0132 & 0.0009 \\
$\beta_{7}$ & 0 & 0.0035 & $\tau_{2}$ & 0.0160 & 0.0005 \\
$\beta_{8}$ & 0 & 0.0057 & $\tau_{3}$ & 0.0024 & 0.0001 \\
$\beta_{x}$ & 0.0468 & 0.0004 & $\tau_{4}$ & 0.0001 & 0.0006 \\
$\gamma$ & 0.6529 & 0.0075 & $\tau_{5}$ & 0 & 0.0002 \\
$\gamma_{x}$ & 0.7798 & 0.0279 & $\tau_{6}$ & 0 & 0.0003 \\
$\gamma_{\pi}$ & 0.3462 & 0.1056 & $\tau_{7}$ & 0 & 0.0003
\end{tabular}




\section{References}

[1] Ang, A. and M. Piazzesi (2003), "A No-Arbitrage Vector Autoregression of Term Structure Dynamics with Macroeconomic and Latent Variables", Journal of Monetary Economics, 50, 745-787.

[2] Ang, A., M. Piazzesi and M. Wei (2006), "What Does the Yield Curve Tell us about GDP Growth?", Journal of Econometrics, 131, 359-403.

[3] Backus, D. and J. Wright (2007), "Cracking the conundrum", Brookings Papers on Economic Activity, 1:2007.

[4] Barro, R. J. and X. Sala-i-Martin (1999), Economic Growth, MIT Press.

[5] Bjornland, H. C., K. Leitemo and J. Maih (2006), "Estimating the Natural Rates in the New-Keynesian Framework", Norges Bank, mimeo.

[6] Boivin, J. and M. P. Giannoni (2005), "DSGE Models in a Data-Rich Environment", Columbia Business School, mimeo.

[7] Campbell, J. Y. and L. M. Viceira (2001), "Who Should Buy Long Term Bonds?", American Economic Review, 91, 99-127.

[8] Clarida, R., J. Gali and M. Gertler (2000), "Monetary Policy Rules and Macroeconomic Stability", Quarterly Journal of Economics, 65, 147-180.

[9] Cogley, T. and T. Sargent (2001), "Evolving Post-World War II U.S. Inflation Dynamics", NBER Macroeconomics Annual, 16, 331-373.

[10] Cox, J. C., J. E. Ingersoll and S. Ross (1985), "A Theory of the TermStructure of Interest Rates", Econometrica, 53, 373-384.

[11] Dai, Q. and K. J. Singleton (2000), "Specification Analysis of Affine Term Structure Models", Journal of Finance, 55, 1943-78.

[12] Derby, M. S. (2004), "Fed Watch: Fed Struggles to Define Neutral Rate Policy", Dow Jones Capital Markets Report.

[13] Duffie, D. and R. Kan (1996), "A Yield-Factor Model of Interest Rates", Mathematical Finance, 6, 379-406.

[14] Estrella, A. and F. S. Mishkin (1997), "The Predictive Power of the TermStructure of Interest Rates in Europe and the United States: Implications for the European Central Bank", European Economic Review, 41, 13751401.

[15] Evans, C. L. and D. A. Marshall (1998), "Monetary Policy and the Term Structure of Nominal Interest Rates: Evidence and Theory", CarnegieRochester Conference Series on Public Policy, 49, 53-111. 
[16] Fagan, G., J. Henry and R. Mestre (2001), "An Area-Wide Model (AWM) for the Euro Area", ECB Working Paper Series, 42.

[17] Friedman, B. M. (1980), "Survey Evidence on the 'Rationality' of Interest Rate Expectations", Journal of Monetary Economics, 6, 453-465.

[18] Froot, K. A. (1989), "New Hope for the Expectations Hypothesis of the Term Structure of Interest Rates", Journal of Finance, 44, 283-305.

[19] Giannoni, M. P. and J. Boivin (2005), "DSGE Models in a Data-Rich Environment", Computing in Economics and Finance, 431.

[20] Goto, S. and W. N. Torous (2003), "The Conquest of U.S. Inflation: Its Implications for the Fisher Hypothesis and the Term Structure of Interest Rates", mimeo.

[21] Hoenig, T. M. (2005), "The U.S. Economic Outlook and Monetary Policy under an Inflation Watch", Remarks at the Wichita Bankers' Forum, Wichita, Kansas, June 16th.

[22] Hördal, P., O. Tristani and D. Vestin (2006), "A Joint Econometric Model of Macroeconomic and Term Structure Dynamics", Journal of Econometrics, 131, 405-444.

[23] Kim, D. H. and A. Orphanides (2005), "Term Structure Estimation with Survey Data on Interest Rate Forecasts", Finance and Economics Discussion Series of the Federal Reserve Board, 48/2005.

[24] Kim, D. H. and J. Wright (2005), "An Arbitrage-Free Three-Factor Term Structure Model and the Recent Behavior of Long Term Yields and DistantHorizon Forward Rates", Finance and Economics Discussion Series of the Federal Reserve Board, 33/2005.

[25] Kremer, M. and M. Rostagno (2006), "The Long-Term Interest Rate 'Conundrum' in the Euro Area: Potential Explanations and Implications for Monetary Policy", European Central Bank, mimeo.

[26] Laubach, T. and J. C. Williams (2003), "Measuring the Natural Rate of Interest", The Review of Economics and Statistics, 85(4), 1063-1070.

[27] Pericoli, M. and M. Taboga (2008), "Canonical Term Structure Models with Observable Factors and the Dynamics of Bond Risk Premia", Journal of Money Credit and Banking, 40, 1471-1488.

[28] Rudebusch, G. D. and L. E. O. Svensson (1999), "Policy Rules for Inflation Targeting", in Monetary Policy Rules, University of Chicago Press, 203-253.

[29] Rudebusch, G. D., E. T. Swanson and T. Wu (2006), "The Bond-Yield Conundrum from a Macro-Finance Perspective", Monetary and Economic Studies of the Institute for Monetary and Economic Studies of the Bank of Japan, 24, 83-109. 
[30] Rudebusch, G. D. and T. Wu (2004), "A Macro-Finance Model of the Term Structure, Monetary Policy and the Economy", Proceedings of the Federal Reserve Bank of San Francisco, March 2004.

[31] Stock, J. H. and M. W. Watson (1998), "Median Unbiased Estimation of Coefficient Variance in a Time-Varying Parameter Model", Journal of the American Statistical Association, 93(441), 349-358.

[32] Vasicek, O. (1977), "An Equilibrium Characterization of the TermStructure", Journal of Financial Economics, 5, 177-188.

[33] Wicksell, K. (1936), Interest and Prices, Macmillan, London. 
Figure 1 - Expected short rate 9-years ahead and forward rate - USA (65-06) Standard Macro-VAR

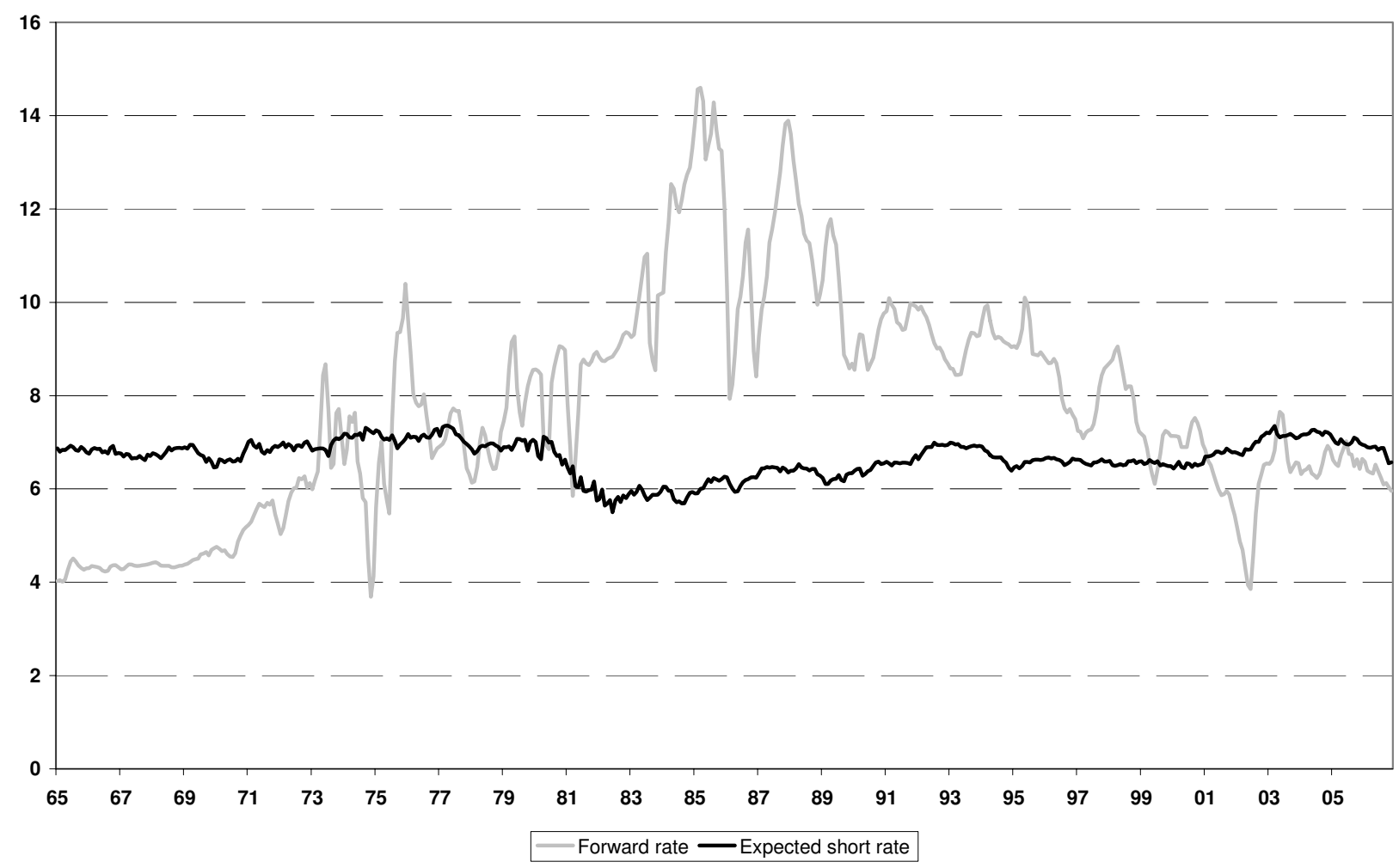

Figure 2 - Expected short rate 9-years ahead and forward rate - USA (65-06) No-Arbitrage Macro-VAR with Latent Factors

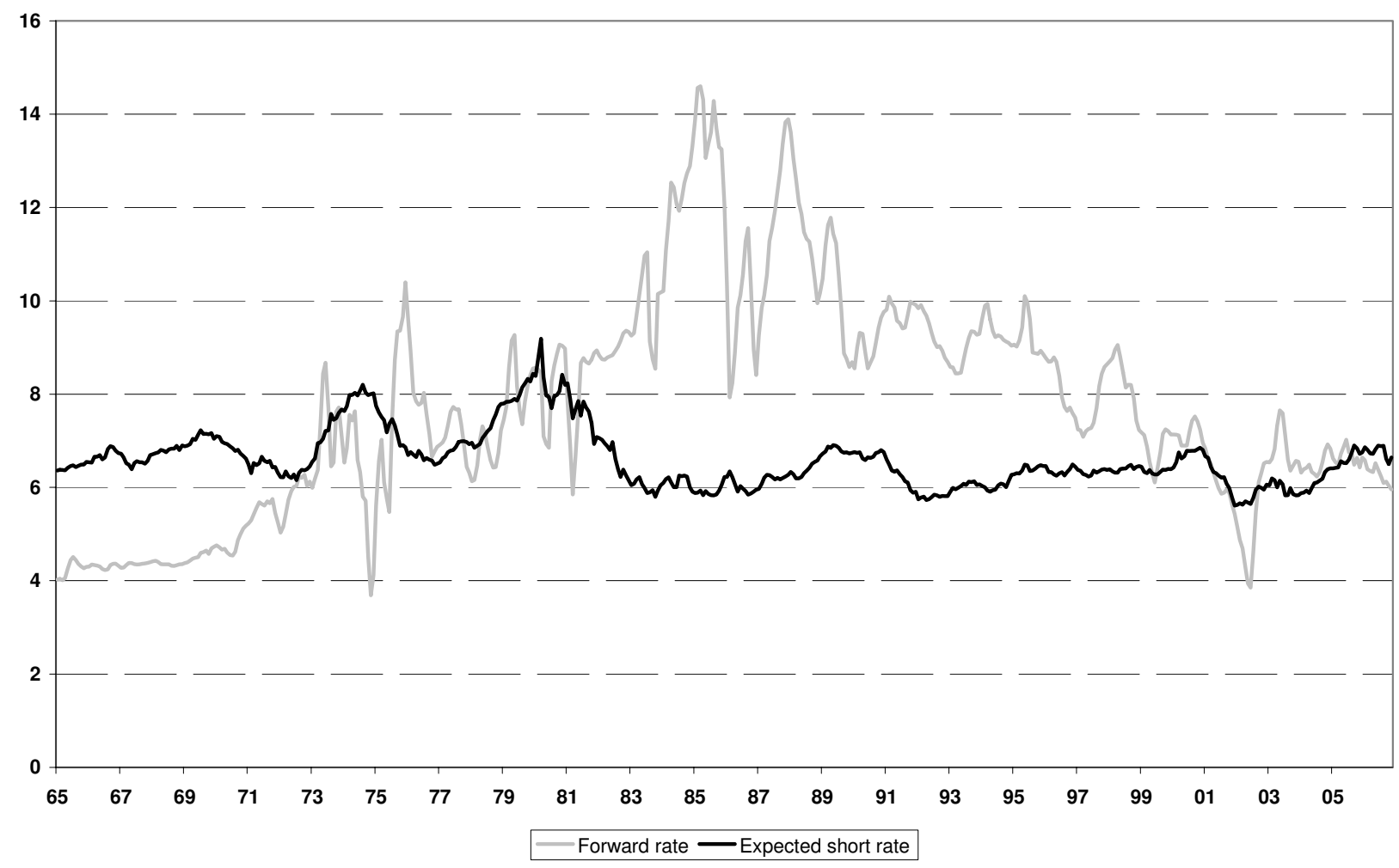


Figure 3 - Expected short rate 9-years ahead and forward rate - USA (65-06) Model with multiple equilibria

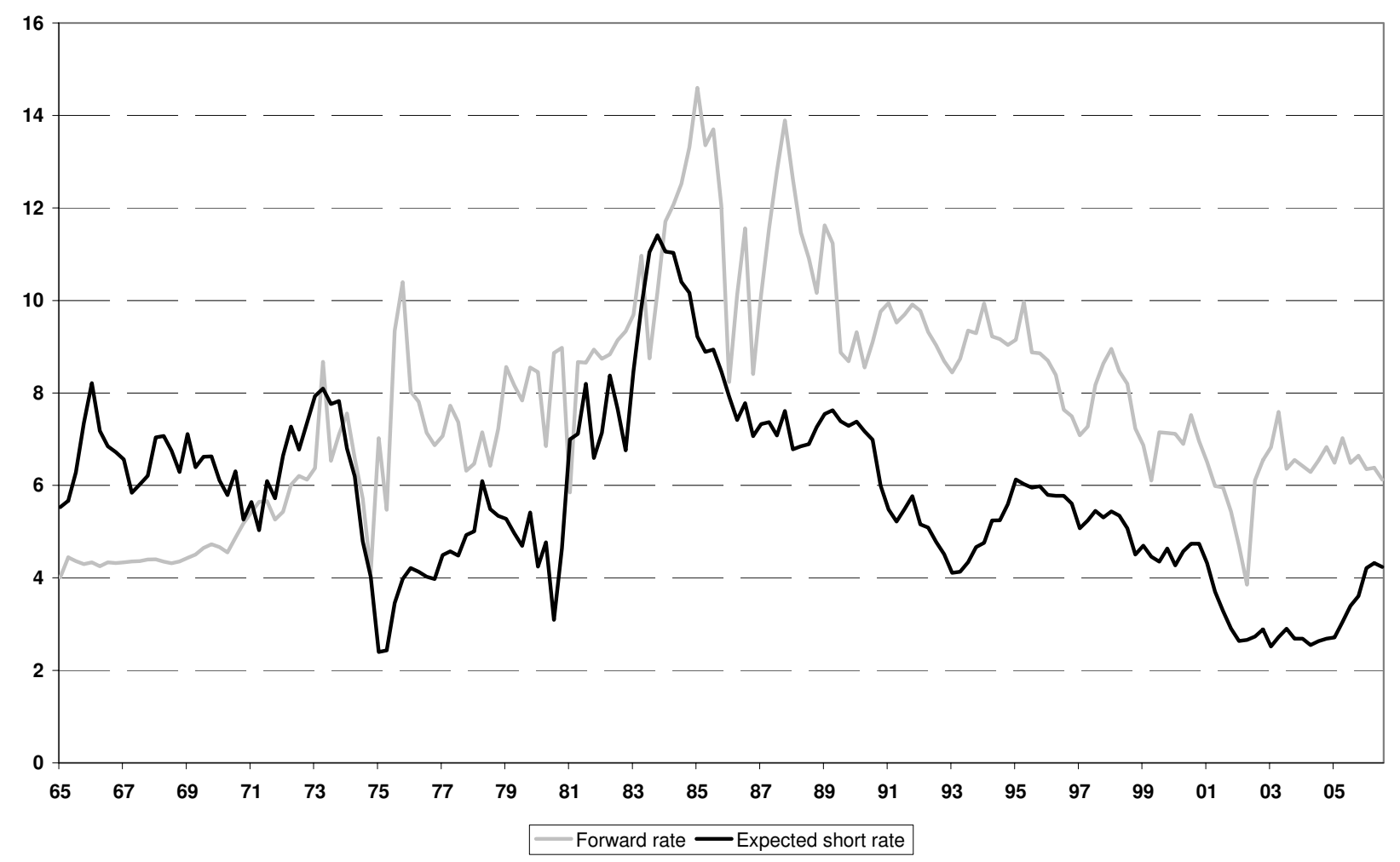

Figure 4 - Expected long-run inflation and the real natural rate - USA (65-06) Model with multiple equilibria

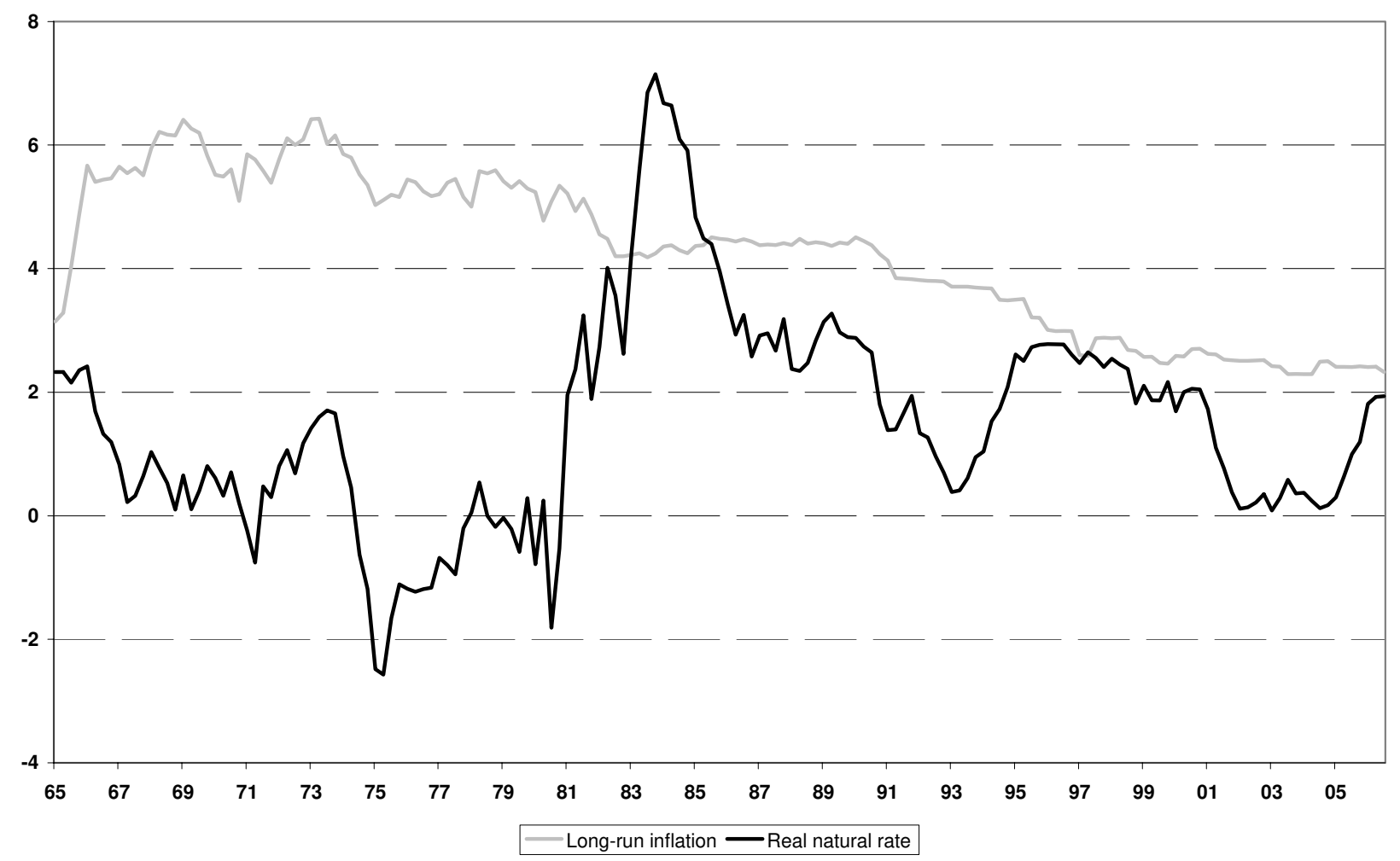


Figure 5 - Estimated forward premium - USA (65-06)

Model with multiple equilibria and standard VAR

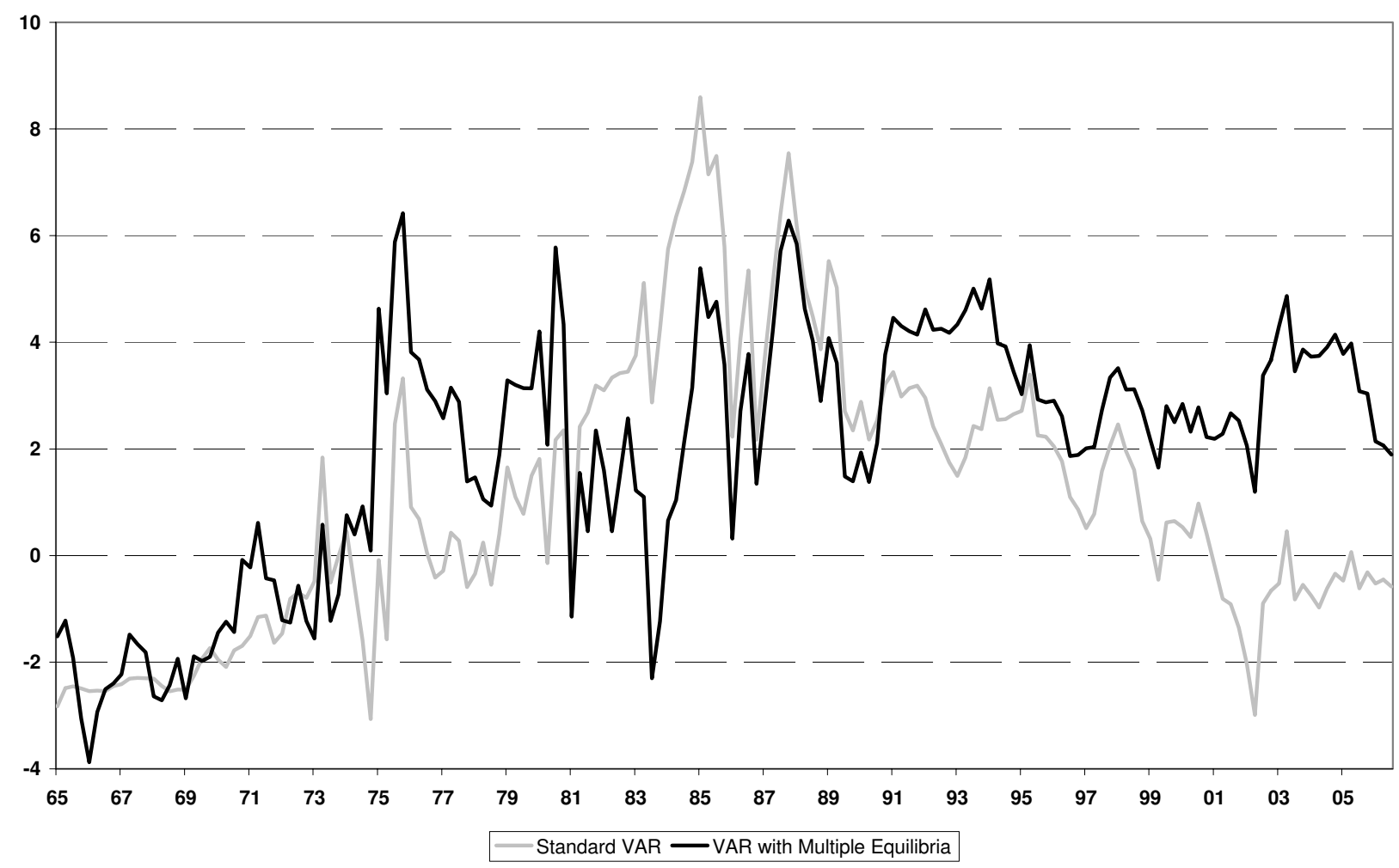

Figure 6 - Estimated forward premium - USA (65-06)

Model with multiple equilibria and no-arbitrage macro-VAR

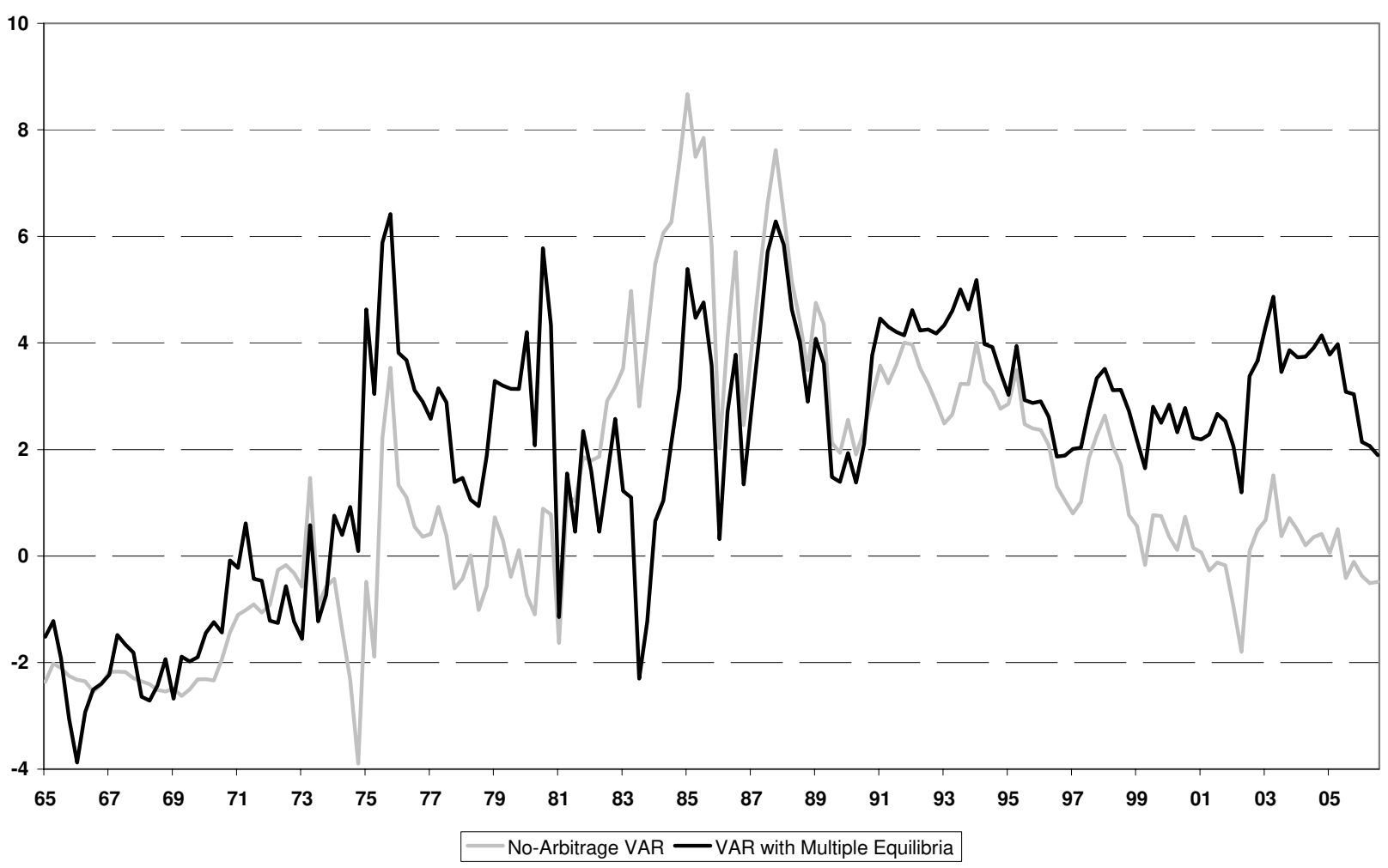


Figure 7 - Expected short rate 9-years ahead and forward rate - Euro Area (80-06) Standard Macro-VAR

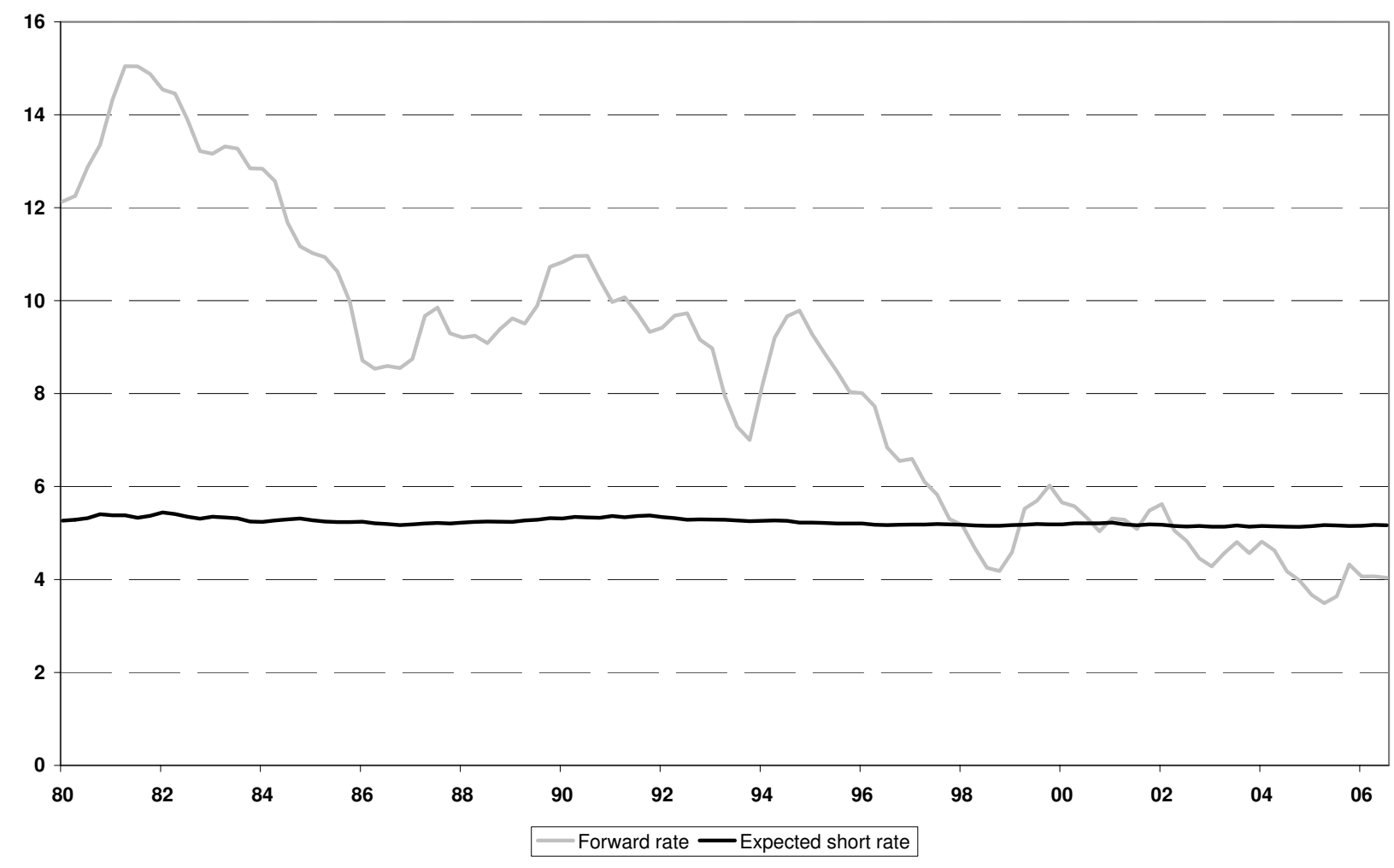

Figure 8 - Expected short rate 9-years ahead and forward rate - Euro Area (80-06) No-Arbitrage Macro-VAR with Latent Factors

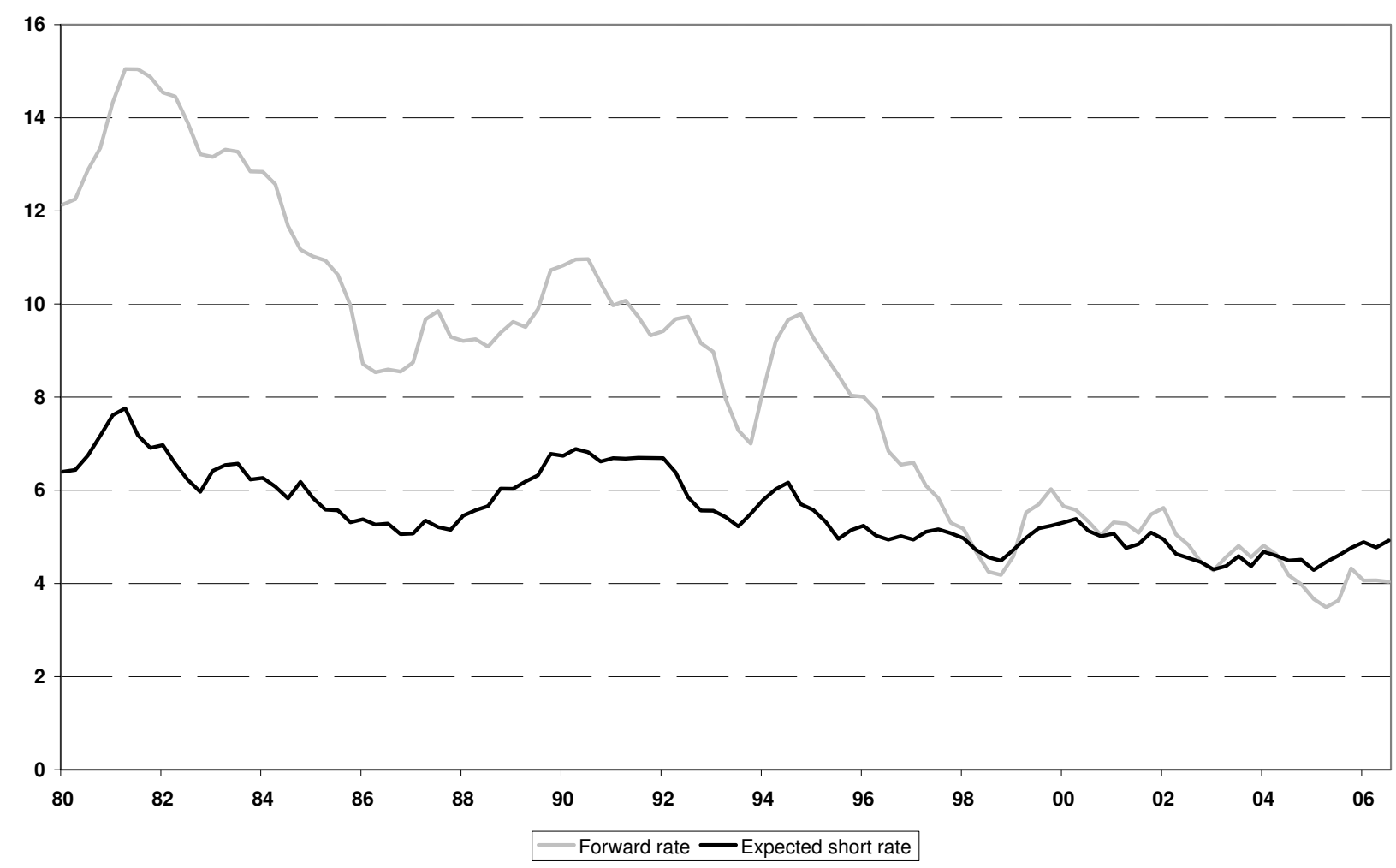


Figure 9 - Expected short rate 9-years ahead and forward rate - Euro Area (80-06) Model with multiple equilibria

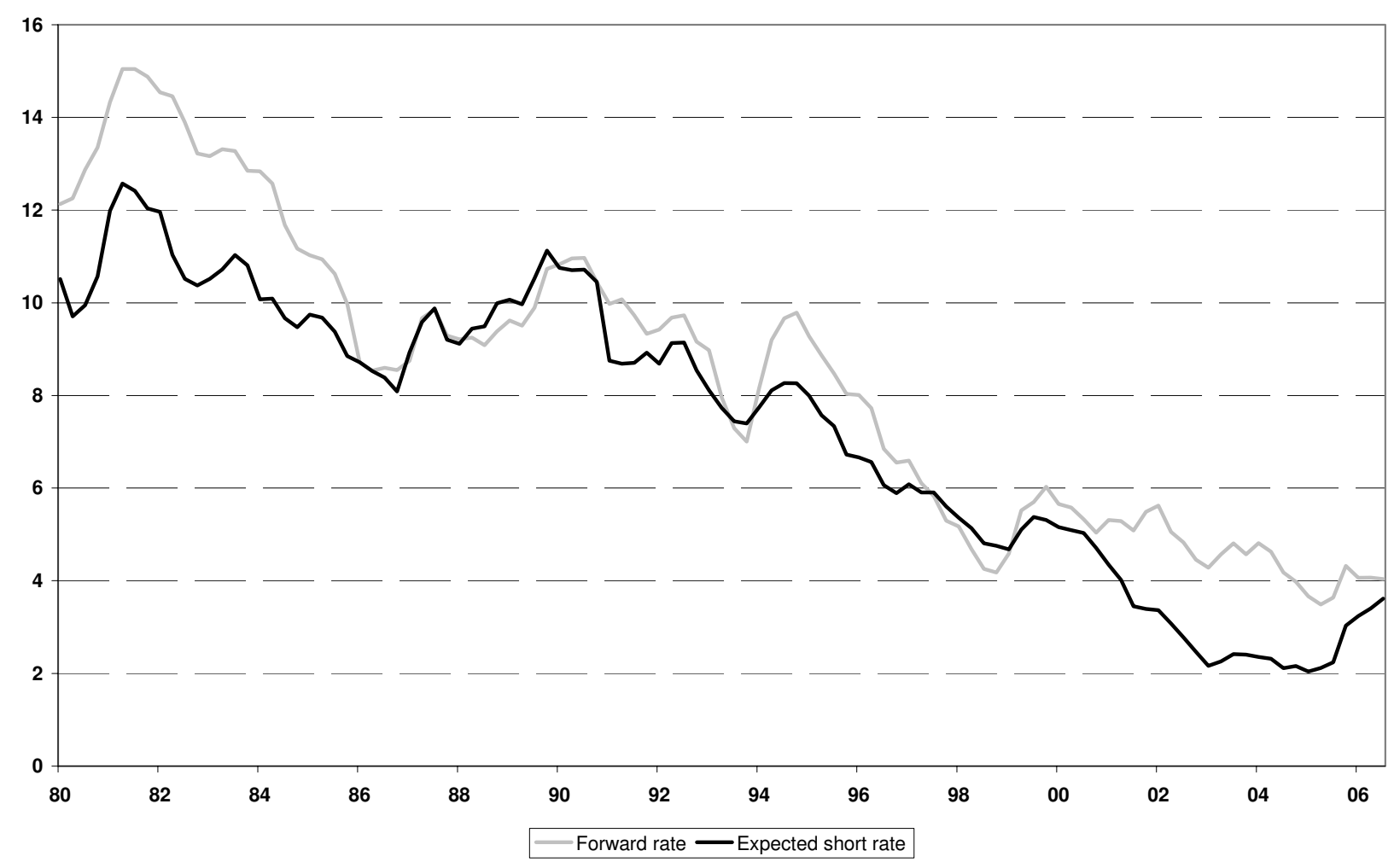

Figure 10 - Expected long-run inflation and the real natural rate - Euro Area (80-06) Model with multiple equilibria

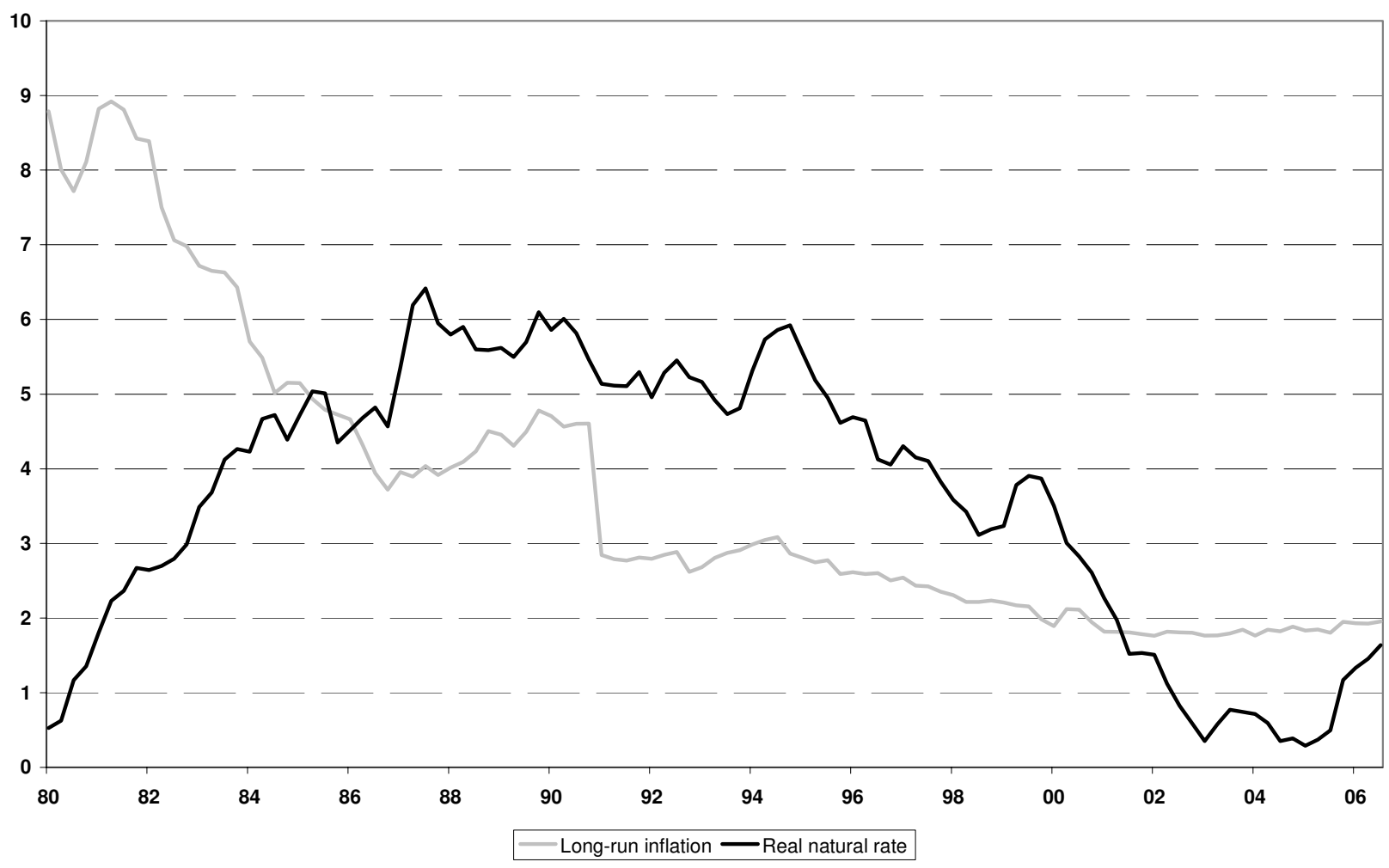


Figure 11 - Estimated forward premium - Euro Area (80-06)

Model with multiple equilibria and standard VAR

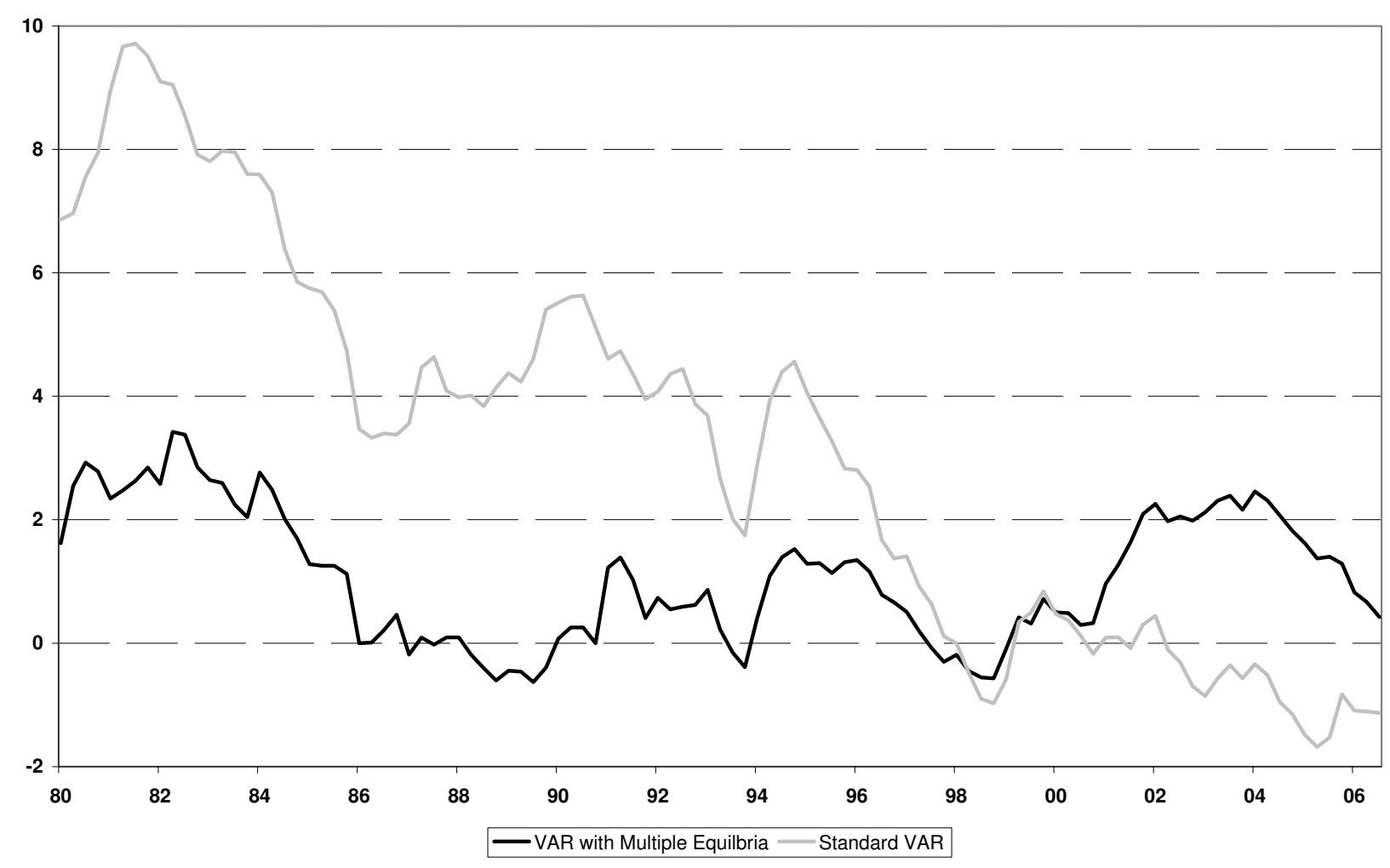

Figure 12 - Estimated forward premium - Euro Area (80-06)

Model with multiple equilibria and no-arbitrage macro-VAR

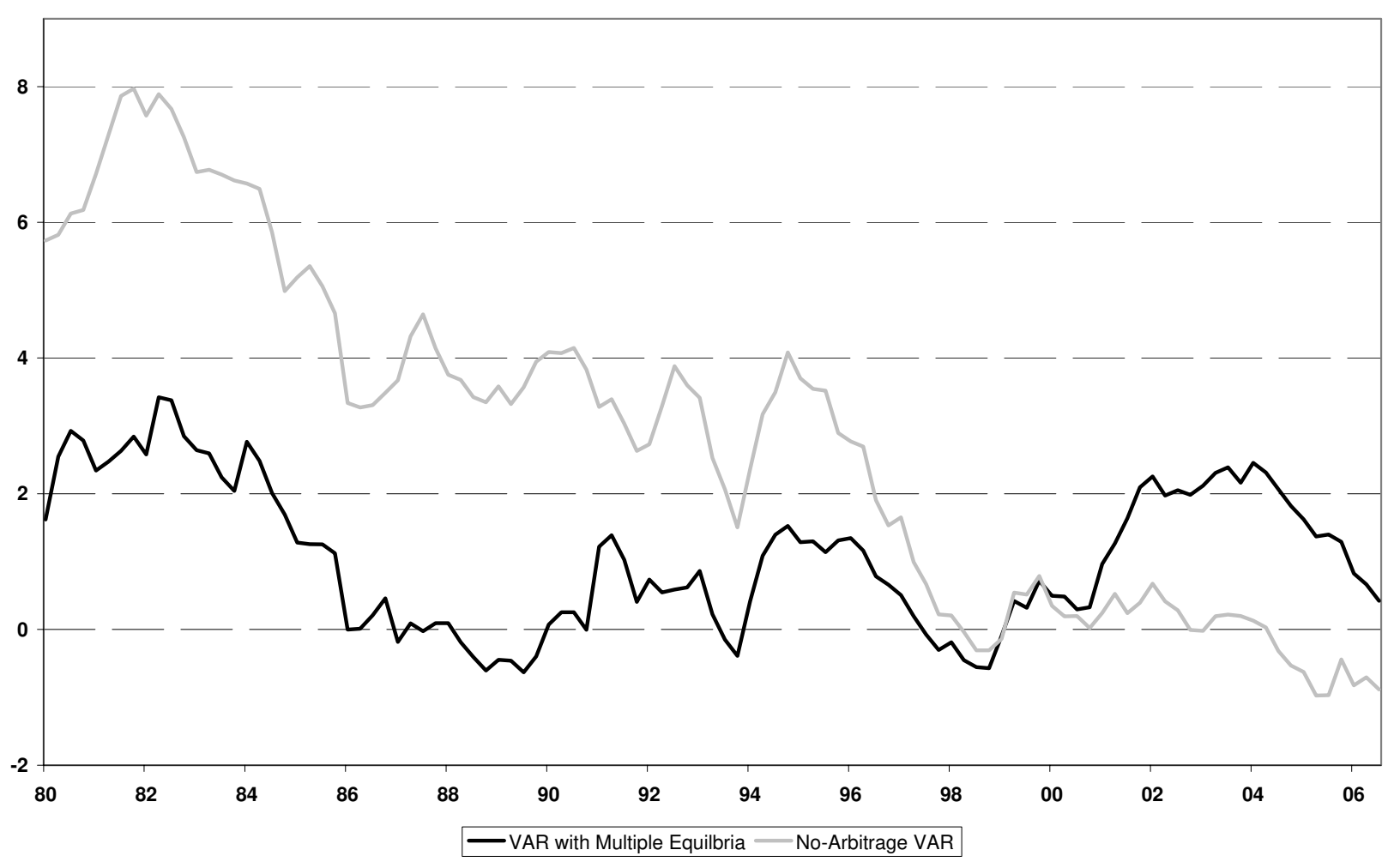

